\title{
(- OPEN ACCESS \\ Heated tobacco product regulation under US law and the FCTC
}

\author{
Lauren Kass Lempert, ${ }^{1}$ Stanton A Glantz ${ }^{1,2}$
}

${ }^{1}$ Center for Tobacco Control Research and Education University of California San Francisco, San Francisco, California, USA

${ }^{2}$ Division of Cardiology, Department of Medicine, University of California San Francisco, San Francisco, California, USA

\section{Correspondence to}

Lauren Kass Lempert, Center for Tobacco Control Research and Education, University of California San Francisco, San Francisco, CA 94143, USA; Lauren.Lempert@ucsf.edu

Received 10 June 2018 Accepted 17 September 2018 Published Online First 5 October 2018
Check for updates

(C) Author(s) (or their employer(s)) 2018. Re-use permitted under CC BY-NC. No commercial re-use. See rights and permissions. Published by BMJ.

To cite: Lempert LK Glantz SA. Tob Control 2018;27:s118-s125.

\section{ABSTRACT}

Tobacco companies are marketing new 'heated tobacco products' (HTPs) composed of battery-powered holders, chargers and tobacco plugs or sticks. The non-tobacco HTP components have escaped effective regulation under many countries' tobacco control laws because they are packaged and sold separately from the tobacco-containing components. In the USA, HTPs cannot be marketed unless the Food and Drug Administration determines that allowing their sale would be 'appropriate for the protection of the public health'. Philip Morris International (PMI) is seeking permission to market its IQOS HTP in the USA with 'modified risk tobacco product' (MRTP) claims that it reduces exposure to harmful substances and is less harmful than other tobacco products. However, PMI has not submitted adequate scientific evidence required by US law to demonstrate that the product is significantly less harmful to users than other tobacco products, that its labelling would not mislead consumers, or that its marketing — with or without MRTP claims - would benefit the health of the population as a whole. Parties to the WHO Framework Convention on Tobacco Control (FCTC) must take measures to reduce tobacco use and nicotine addiction, and prevent false or misleading tobacco product labelling, advertising and promotions; the introduction of new HTPs must be assessed according to these goals. All components of HTPs should be regulated at least as stringently as existing tobacco products, including restrictions on labelling, advertising, promotion and sponsorship, sales to minors, price and taxation policies and smokefree measures. There is nothing in US law or the FCTC that prevents authorities from prohibiting HTPs.

'Heated tobacco products' (HTPs), also known as 'heat-not-burn' products, ${ }^{1}$ use battery-powered systems to heat sticks of compressed tobacco, flavours and other chemicals to produce a nicotine aerosol to create a 'nicotine hit' that imitates cigarette smoking. ${ }^{2}$ A commercial failure in previous decades, ${ }^{1}$ major tobacco companies now promote HTPs in many countries as less harmful alternatives to conventional cigarettes, including Philip Morris International's (PMI) 'IQOS', Japan Tobacco International's 'Ploom TECH' and British American Tobacco's (BAT) 'glo'.3

The US Family Smoking Prevention and Tobacco Control Act ${ }^{4}$ (TCA) assigned the Food and Drug Administration (FDA) authority to regulate tobacco products, including modified (reduced) risk tobacco products (MRTP). The TCA requires premarket authorisation of all tobacco products (Section $910)^{4}$ and does not permit manufacturers to market tobacco products with claims that they are 'modified risk tobacco products' (ie, the product is sold to reduce harm or the risk of tobacco-related disease, or to reduce consumers' exposure to harmful substances) without first demonstrating to FDA that these claims are supported by scientific evidence. (Section 911) ${ }^{4}$ FDA must refer all MRTP applications (MRTPA) to its Tobacco Products Scientific Advisory Committee (TPSAC) which must report its recommendations (which are advisory only) to FDA. (Section 911(f)) ${ }^{4}$

Outside the USA, the WHO Framework Convention on Tobacco Control $^{5}$ (FCTC, the USA is not a party), and its implementing guidelines ${ }^{6}$ provide frameworks for parties to enact implementing national legislation, including prohibitions on misleading advertising (Article 11(1)(a)) ${ }^{5}$ (Article 11 Guidelines for Implementation $)^{6}$ and misleading packaging and labelling (Article 13(4)(a)) $)^{5}$ (Article 13 Guidelines for Implementation) ${ }^{6}$ which serve similar purposes as MRTP review. Further, parties are 'encouraged to implement measures beyond those required' by the FCTC. (Article 2$)^{5}$

When the TCA and FCTC were enacted, the tobacco companies were not marketing their current HTPs. This paper uses the specific case of IQOS to analyse how these regulatory frameworks do or should apply to HTPs and related reduced harm claims.

\section{THE IQOS HTP IS AN INTEGRATED TOBACCO PRODUCT DESIGNED TO MAINTAIN NICOTINE ADDICTION}

IQOS consists of three integrated components essential for its proper functioning: a holder (which heats the tobacco material via an electronically controlled heating blade), a charger (which recharges the holder after each use) and a tobacco stick ('HeatSticks' or 'HEETS') (figure 1). As PMI acknowledges, these three components collectively comprise IQOS $^{7}$; the holder and charger have no independent function without the tobacco sticks, and the tobacco sticks cannot create a nicotine aerosol without the holder and charger. In its MRTP application, PMI describes the HeatStick as 'specifically designed to function with the holder to produce an aerosol [emphasis added]'.8

PMI is taking advantage of this three-component design to package and sell the tobacco sticks separately from other IQOS components that do not contain tobacco, thereby evading existing tobacco control labelling, marketing and tax laws in some countries. For example, in Canada many chain convenience stores sell IQOS HEETS, but not the device itself, and store clerks inform customers to contact an IQOS representative to arrange for the 
$\mathbf{A}$

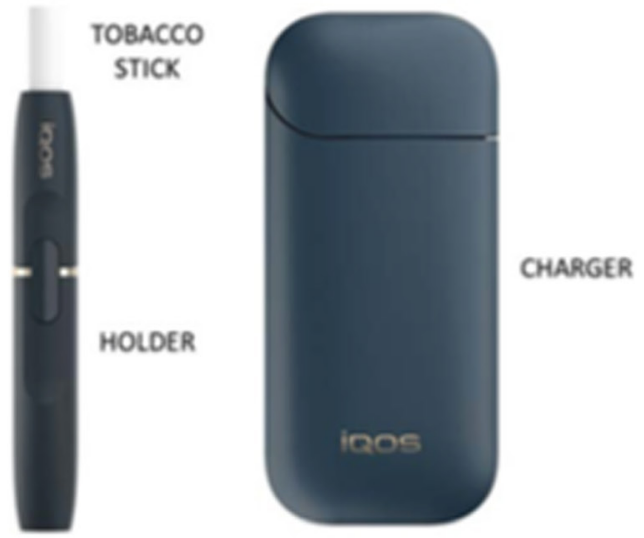

B

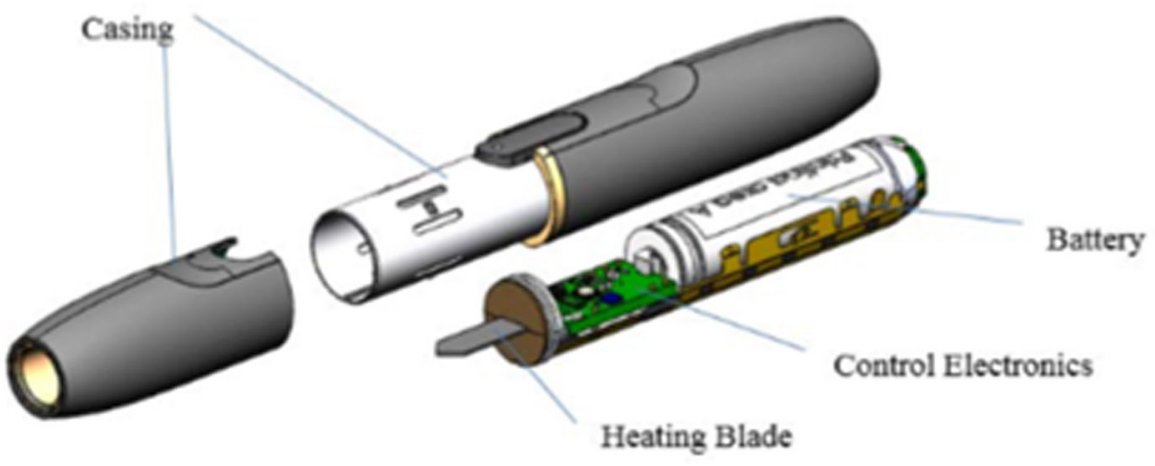

C

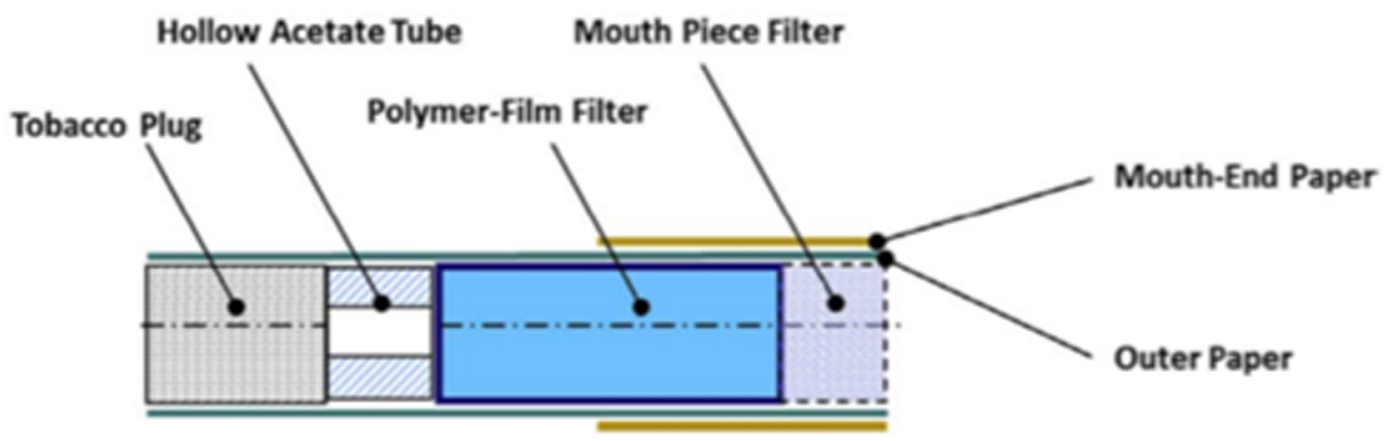

Figure 1 Schematic drawing of the IQOS showing its components (A), a schematic exploded view drawing of the holder (B), and a schematic crosssectional view of the tobacco stick (C) (Executive Summary). ${ }^{7}$

device purchase. ${ }^{9}$ In Korea, ${ }^{10}$ PMI markets its IQOS holder, charger and related accessories in packages that do not contain the HEETS labelled only as 'IQOS' without any reference to tobacco or health warnings required on tobacco product packaging. PMI sells the HEETS in separate packages branded with Marlboro or other cigarette brands that include health warnings and comply with tobacco product packaging and labelling laws.

The product description of IQOS in PMI's MRTPA is heavily redacted, ${ }^{7}$ but states that the IQOS holder contains an electronic chip (firmware) used to 'control the temperature', 'detect puffs' and conduct other functions that control the user's nicotine intake. (Module 3.1, Product Description) ${ }^{7}$ PMI testified at the January 2018 TPSAC meeting that the
IQOS device is able to capture data such as the number of puffs taken, but said this information is used for diagnostic purposes if the device is returned. ${ }^{11}$ Additionally, PMI testified to TPSAC that IQOS's Bluetooth functionality is used to deliver messages to consumers such as 'you haven't used your IQOS device today' and to remind them to reorder tobacco HeatSticks. ${ }^{11}$ The fact that IQOS measures a user's puff-by-puff heating profile, ${ }^{11} 12$ integrates IQOS's Bluetooth capability with mobile phones and computers, ${ }^{13}$ and automatically reminds consumers to continuously use the device and to reorder tobacco sticks ${ }^{11}$ suggests that it calibrates the delivery of nicotine to ensure not only 'satisfaction', but also the potential for PMI to customise the dose, speed of delivery 
and continuous use of nicotine to maximise addictive potential for individual users. ${ }^{12} 1415$

\section{REGULATION OF HTPS IN THE USA}

How tobacco products are defined impacts how they are regulated. ${ }^{16}$ The TCA defines 'tobacco products' as 'any product made or derived from tobacco that is intended for human consumption, including any component, part, or accessory of a tobacco product... [emphasis added]'. (Section 101(a) ${ }^{4}$ IQOS (including the HeatSticks, holder and charger) falls squarely under the FDA's definition of 'tobacco product'; PMI does not dispute that its IQOS product (including all three components) is a 'tobacco product' under US law ${ }^{7}$ and subject to most regulations that pertain to tobacco products (eg, premarket review $(\text { Section } 910)^{4}$ ) and prohibition on distribution of free samples. ${ }^{17}$

The Deeming Rule, in which FDA took jurisdiction over tobacco products beyond cigarettes and smokeless tobacco, defines 'component or part' to include materials intended or expected to alter or affect the tobacco product's performance, composition or characteristics ${ }^{18}$ and extends FDA's regulatory authority to cover all tobacco products meeting the definition of 'tobacco product' including HTPs and their components and parts. ${ }^{19}$ Certain provisions of the Deeming Rule (eg, prohibition of sales to customers under age 18 and vending machine sales) ${ }^{20}$ apply only to 'covered tobacco products' which 'excludes any component or part that is not made or derived from tobacco'. ${ }^{18} 20$ The loophole FDA created in the Deeming Rule contradicts the clear definition of 'tobacco product' in the $\mathrm{TCA}^{4}$ which includes 'any component, part, or accessory'. The loophole creates opportunities for companies to sell IQOS devices to youth in violation of the law's intent.

Additionally, the Federal Cigarette Labeling and Advertising $\mathrm{Act}^{21}$ (FCLAA) defines 'cigarettes' as 'any roll of tobacco wrapped in paper or in any substance not containing tobacco' and the regulations implemented under the TCA incorporated this definition. ${ }^{18}$ Because the HeatSticks also meet the definition of 'cigarettes', additional restrictions that apply to cigarettes but not other tobacco products (eg, required cigarette warnings ${ }^{22}$ and prohibition of advertising on electronic communication media ${ }^{23}$ ) should apply to the HeatSticks.

Before being permitted to market a new tobacco product in the USA, manufacturers must first receive premarket authorisation from FDA through a premarket tobacco product application (PMTA), a 'substantial equivalence' (SE) order or an exemption from SE. (Section 910(a)(2)) ${ }^{4}$ (The less rigorous SE pathway is not available to the current generation of HTPs because no HTPs with similar characteristics were marketed in the USA before 15 February 2007, (Section 910(a)(3)) ${ }^{24}$ and HTPs are not 'minor modifications' of any product that was marketed in the USA before 15 February 2007. (Section 905(j)(3)) $)^{24}$ ) A PMTA applicant has the burden of showing that the product 'would be appropriate for the protection of the public health', determined with respect to 'the risks and benefits to the population as a whole, including users and nonusers', taking into account the increased or decreased likelihood that existing users will stop using tobacco products, and non-users will start using them. (Section 910(c)(4)) ${ }^{4}$ This stringent standard essentially requires the applicant to demonstrate that, on balance, 'allowing the sale of the new product would likely reduce tobacco-related harms'. ${ }^{25}$ Additionally, FDA is required to deny a PMTA for any product whose proposed labelling is 'false or misleading in any particular'. (Section 910(c) $(2)(\mathrm{C}))^{4}$
Furthering its mission to protect the public health, the TCA aims to prevent the tobacco industry deception detailed in a US district court's holding that tobacco companies deliberately deceive and mislead consumers about the harmfulness of their products with labelling and marketing ${ }^{26} 27$ and highlighted in the TCA's 'Findings' section. (Section 2$)^{4}$ In particular, the TCA gives FDA the authority to 'ensure that there is effective oversight of the tobacco industry's efforts to develop, introduce, and promote less harmful tobacco products'. (Section 3(4)) ${ }^{4}$

The TCA defines an MRTP as 'any tobacco product that is sold or distributed for use to reduce harm or the risk of tobacco-related disease associated with commercially marketed products.' (Section 911(b)(1)) ${ }^{4}$ To secure an order permitting sales of tobacco products with modified-risk claims, a manufacturer must submit an application (MRTPA) to FDA demonstrating that the product, as actually used by consumers, will 'significantly reduce harms and the risk of tobacco-related disease to individual tobacco users' and 'benefit the health of the population as a whole', taking into account both users and non-users of tobacco products. (Section 911(g)(1)) ${ }^{4}$ For products that cannot receive risk-modification orders, FDA may issue an exposure-modification order if the applicant has demonstrated that doing so 'would be appropriate to promote the public health' and the labelling and advertising is limited to representing that the product or its smoke is free of or contains a reduced level of a substance or presents a reduced exposure to a substance in tobacco smoke. (Section 911(g)(2) $(\mathrm{A}))^{4}$ Additionally, for an exposure-modification order, the applicant must demonstrate among other things that: (1) the product as actually used by consumers will not expose them to higher levels of other harmful substances compared with similar types of tobacco products currently on the market and its use would reduce overall morbidity and mortality among users; and (2) based on testing of actual consumer perception, the proposed labelling and marketing will not mislead consumers into believing that the product is less harmful or presents less risk of disease than other commercially marketed tobacco products. (Section 911(g)(2)(B)) ${ }^{4}$ Furthermore, for both risk-modification and exposure-modification orders, FDA must ensure that 'any advertising and labeling concerning modified risk products enable the public to comprehend the information concerning modified risk and to understand the relative significance of such information in the context of total health' and tobacco-related harms. (Section 911(h)(1)) ${ }^{4}$

The TCA authorises states to enact laws that are more stringent than TCA requirements, including measures 'prohibiting the sale, distribution, possession, exposure to, access to, advertising and promotion of, or use of tobacco products by individuals of any age'. (Section 916)

\section{The PMI IQOS MRTP application}

In December 2016, PMI submitted a multimillion-page MRTPA to FDA seeking permission to market IQOS in the USA with two modified-risk claims ('switching completely from cigarettes to the IQOS system can reduce the risks of tobacco-related diseases' and 'switching completely to IQOS presents less risk of harm than continuing to smoke cigarettes') and one modified-exposure claim ('switching completely from cigarettes to the IQOS system significantly reduces your body's exposure to harmful and potentially harmful chemicals'). ${ }^{7}$ In January 2018, PMI presented its IQOS MRTPA to TPSAC, and TPSAC found that PMI's MRTPA failed to provide sufficient scientific evidence supporting its modified risk claims. ${ }^{11} 13$ 
In March 2017, PMI submitted a PMTA ${ }^{28}$ seeking authorisation to market IQOS in the USA which is required whether or not IQOS is marketed with MRTP claims. Accordingly, if FDA rejects PMI's application to market IQOS with MRTP claims, FDA could still grant PMI's application to market IQOS in the USA without any such claims.

PMI's harm-reduction claims are based on the principle that it is the inhalation of complex combustion compounds in tobacco smoke that causes adverse health outcomes, and since the IQOS device purportedly heats but does not burn the proprietary tobacco stick to create an inhalable nicotine-containing aerosol, it is less harmful than cigarette smoke. ${ }^{8}$ Contrary to these claims, harmful chemicals are created in the pyrolysis phase. ${ }^{29}$

US law (Section 911(g)(1)) ${ }^{4}$ places the burden on PMI to demonstrate that IQOS is appropriate for the protection of the public health before marketing it with MRTP claims and not on FDA or the public to demonstrate the product's harmfulness. However, a close reading of PMI's MRTPA reveals it did not meet this burden. PMI's own data fail to show consistently lower risks of harm in humans using IQOS compared with conventional cigarettes, ${ }^{30} 31$ that IQOS is associated with pulmonary and immunomodulatory harms not significantly different from conventional cigarettes, ${ }^{32} 33$ that IQOS use may be associated with hepatotoxicity and unexpected organ toxicity that has not been associated with conventional cigarettes ${ }^{34} 35$ and that IQOS use does not necessarily avoid the adverse cardiovascular effects of conventional cigarette smoking. ${ }^{36} 37$ In addition, data collected independently of PMI revealed IQOS does not consistently reduce exposure to harmful or potentially harmful chemicals. ${ }^{29}$ 38-42 Moreover, Reuters published a report in December 2017 identifying irregularities in PMI's IQOS research. ${ }^{43}$ At its January 2018 meeting, TPSAC voted that PMI's MRTPA failed to provide scientific evidence supporting its modified risk claims. $^{13}$

The evidence presented in PMI's MRTPA also failed to demonstrate a net public health benefit as required for both a PMTA order (Section 910(c)(4) $)^{4}$ and a MRTP order. (Section 911(g) (1) $)^{4}$ PMI did not demonstrate IQOS would benefit the health of the population as a whole, considering both users and non-users of tobacco products. ${ }^{45} 46$ Of particular concern, PMI failed to consider whether youth or adolescents or other non-users are likely to initiate tobacco use with IQOS, ${ }^{104748}$ or whether users are likely to use IQOS concurrently with other tobacco products, rather than 'switch completely'. 324749 Based on the evidence presented in PMI's MRTPA, TPSAC found that there would be a low likelihood that US smokers would completely switch to IQOS use. ${ }^{13}$

The TCA also requires PMI's MRTPA to include scientific studies demonstrating that consumers will understand the proposed advertising and labelling and not be misled into believing the product is less harmful than it actually is. However, the evidence presented by PMI indicates that the IQOS labelling or advertising will not ensure accurate consumer perceptions of risk, smokers will not understand they would need to switch completely to IQOS to secure the purported benefits, and consumers will likely view the reduced-exposure claims as reduced-risk claims, rendering them inherently misleading. ${ }^{27} 5051$ Independent research also demonstrates that adults and adolescents misinterpret reduced-exposure claims as communicating lower risk even when there is no explicit claim of lower risk. ${ }^{52}$ TPSAC also found that PMI failed to demonstrate that consumers would accurately understand the risks of IQOS as conveyed in PMI's proposed MRTP labelling and advertising. ${ }^{13}$
If PMI cannot revise its application to demonstrate that marketing IQOS would actually be 'appropriate for the protection of the public health' and its proposed labelling would not be misleading, FDA would be required by statute to deny PMI's applications, and PMI would not be permitted to market IQOS with or without any related modified-risk claims.

FDA's decisions regarding PMI's IQOS applications will influence how other governments regulate HTPs and related reduced-risk claims throughout the world. Indeed, PMI stated in its 2018 annual report, 'We remain focused on our aspiration to see IQOS launched in the United States' and 'Future FDA actions may influence the regulatory approach of other governments'. ${ }^{53}$

\section{REGULATION OF HTPS IN FCTC PARTY COUNTRIES}

The objective of the FCTC is 'to protect present and future generations from the devastating health, social, environmental and economic consequences of tobacco consumption and exposure to tobacco smoke' and to reduce 'continually and substantially the prevalence of tobacco use'. (Article 3$)^{5}$ The 181 parties to the FCTC commit to implementing legislative and other measures 'for preventing and reducing tobacco consumption, nicotine addiction and exposure to tobacco smoke', (Article 5$)^{5}$ to inform every person of 'the health consequences, addictive nature and mortal threat posed by tobacco consumption', to prevent initiation and decreasing the consumption of tobacco products 'in any form', (Article 4$)^{5}$ and to prevent and reduce 'nicotine addiction' in addition to tobacco consumption. (Article 5$)^{5}$

The FCTC provides strong and broad support for parties to adopt measures protecting the public from the dangers of HTPs. Although the FCTC (negotiated between 1999 and 2003) does not specifically discuss HTPs, it was not intended to be limited to conventional cigarettes, smokeless tobacco and other tobacco products being marketed at the time. The objective of the FCTC is unequivocally to protect 'future generations' as well as present generations, (Article 3$)^{5}$ and it anticipates the introduction of new products that would be introduced after treaty negotiations concluded in 2003. FCTC Article 2 encourages parties to implement measures that go beyond and are stricter than those required by the FCTC. (Article 2$)^{5}$ Countries can choose various approaches to regulating HTPs consistent with FCTC's goals.

\section{Regulating HTPs as tobacco products}

FCTC Article 1 defines 'tobacco products' as 'products entirely or partly made of the leaf tobacco as raw material which are manufactured to be used for smoking, sucking, chewing or snuffing'. (Article 1$)^{5}$ Unlike the definition under US law, the FCTC's definition of 'tobacco product' does not explicitly include 'any component, part, or accessory of a tobacco product'. However, because HTPs are integrated products that are partly made of tobacco and are used for smoking or sucking, some countries may interpret their laws to consider HTPs as tobacco products. Significantly, in its own documents and marketing claims, PMI refers to its 'IQOS system' as one integrated tobacco product. PMI states that IQOS's tobacco sticks are 'specifically designed to function with the holder', and refers to IQOS interchangeably as 'IQOS', 'the IQOS system, consisting of the tobacco sticks, holder, and charger' and as 'the Tobacco Heating System'. ${ }^{7}$ On its website, PMI markets the three main IQOS components as a singular tobacco product, the IQOS 'tobacco heating system'. 54

The fact that HTPs are considered 'tobacco products' under the FCTC is confirmed in several statements issued by the Convention Secretariat. ${ }^{55}$ In 2016, the FCTC Conference of the Parties 
(COP), the treaty's governing body, stated that 'All new and emerging tobacco products should be regulated under the WHO FCTC. This should include products such as vaporizers and any other novel devices which can be used for tobacco consumption and are not classified as electronic cigarettes. ${ }^{56}$ A 2017 WHO information sheet on HTPs stated, 'all forms of tobacco use are harmful, including HTPs', and recommended, 'HTPs should be subject to policy and regulatory measures applied to all other tobacco products, in line with the WHO FCTC. ${ }^{57}$

In September 2017, the FCTC Convention Secretariat addressed the introduction of new tobacco products such as HTPs and stated that parties are obligated under the FCTC to treat these and 'other novel tobacco or nicotine products' that may emerge in the same way other tobacco products are regulated. ${ }^{55}$ Thus, parties should include HTPs in all restrictions currently applied to other tobacco products, including but not limited to regulation of the product's contents and disclosures, packaging and labelling requirements, comprehensive bans (or severe restrictions) on product advertising, promotion and sponsorship, protections from exposure to the product's smoke/ aerosol, prohibitions on sales to minors, and price and tax measures.

In March 2017, Israel became the first country to regulate IQOS as a tobacco product and apply all tobacco product restrictions to IQOS ${ }^{58}$ and in March 2018 Israel's Finance Committee approved applying Israel's cigarette tax to IQOS. ${ }^{59}$

\section{Prohibiting HTPs}

The simplest and most effective way to deal with HTPs under the FCTC would be to prohibit the introduction of HTPs which is supported by the FCTC's goals, including protecting future generations from the devastating health consequences of tobacco consumption, (Article 3$)^{5}$ preventing the initiation of tobacco products 'in any form' (Article 4$)^{5}$ and preventing and reducing 'nicotine addiction'. (Article 5) ${ }^{5}$ Historical arguments against banning cigarettes (eg, that it would lead addicted smokers to seek nicotine elsewhere and create a black market) ${ }^{60}$ do not apply to a ban on products like HTPs that have yet to be introduced or are as yet a minor segment of the nicotine market.

By introducing IQOS or other HTPs, tobacco companies are likely to increase tobacco consumption, increase nicotine addiction, increase initiation among youth and non-smokers, ${ }^{61}{ }^{62}$ undermine efforts to denormalise and significantly reduce tobacco use,${ }^{63}$ and create a new market of tobacco products that once established will be difficult to control. PMI has introduced IQOS in some markets where it is treated differently from cigarettes under existing regulatory frameworks, allowing it to advertise IQOS and engage in intensive one-to-one marketing to switch current smokers to IQOS which would not be permitted under those countries' FCTC-aligned tobacco control legislation. ${ }^{960}$ The fact that IQOS could be programmed to maximise addictive potential (discussed above) is of particular concern.

Recent experience with e-cigarettes suggests that introducing new, highly addictive tobacco products where cigarettes are available may increase initiation and encourage dual use, especially among youth, and sustain nicotine addiction in violation of the FCTC's principles. ${ }^{64-66}$

Some FCTC parties have already effectively banned HTPs. For example, in 2015 Singapore banned emerging tobacco products including e-cigarettes and devices that are smoked or mimic smoking. ${ }^{67}$, In Australia, nicotine is a scheduled poison, so products containing nicotine for human consumption are prohibited unless for 'human therapeutic use' (cigarettes are grandfathered). ${ }^{68}$

\section{Definitions in national implementing legislation}

The statutory systems of each of the 181 parties to FCTC differ, and the legal mechanisms for drafting, amending or interpreting laws will be specific to each country. Because many parties enacted national legislation to implement the FCTC before the current generation of HTPs were being marketed, some countries' laws use definitions of 'tobacco products' that are ambiguous with regard to HTPs. Removing any ambiguity or potential for misunderstanding will make it more difficult for tobacco companies to claim there are loopholes that exempt HTPs or any HTP components from tobacco control laws.

As discussed above, tobacco companies are seeking to take advantage of this ambiguity by disassembling their integrated tobacco products and selling the components that do not contain tobacco in separate packages and even separate stores to evade labelling and advertising laws. Parties to the FCTC should ensure that all of the tobacco control measures contained in the FCTC apply to all components of the HTP system, whether sold as a single system or as separate components.

Analogous to the situation where IQOS holders and chargers are sold separately from IQOS tobacco sticks, hookah waterpipes are often sold separately from hookah tobacco. Responding to the potential problems this poses in regulating warning labels, in November 2016 COP issued a decision stressing the need for all parties to fully implement all FCTC articles in all aspects of waterpipe use. ${ }^{69}$ We found one country, Turkey, whose labelling laws explicitly require health warnings to be placed on hookah bottles and waterpipe tobacco packages. ${ }^{70}$

Countries should interpret their definitions to include HTPs (and other new tobacco products), and, if necessary to avoid ambiguity, amend their definitions, for example, 'tobacco products' means products entirely or partly made of tobacco which are manufactured to be used for inhaling, smoking, sucking, chewing, snuffing or by any other means (see, eg, definitions of 'tobacco products' found in Thailand, the Philippines, Cambodia, Oman and Uganda). ${ }^{71}$ Alternatively, countries could add language to clarify that their existing definitions of tobacco products include components like the US definition, and ensuring that all regulations that apply to tobacco products also apply to their components. COP should issue an opinion recommending that parties subject HTPs to all FCTC regulatory measures applied to tobacco products and prohibit tobacco industry attempts to evade these measures.

Countries could also clarify and broaden the definition of 'smoking' in their laws. The FCTC Article 8 Guidelines recommended defining 'smoking' as 'being in possession or control of a lit tobacco product regardless of whether the smoke is being actively inhaled or exhaled'. (Article 8$)^{6}$ Countries that adopted this language should change the definition so that it would clearly include HTPs. This could be accomplished by explicitly adding HTPs to the definition of smoking. COP should issue a decision recommending all parties to ensure their definition of 'smoking' includes HTPs and other new tobacco products that may emerge.

\section{Packaging, advertising and marketing}

FCTC Article 11 requires parties to adopt measures that prohibit packaging and labelling that promotes a tobacco product 'by any means that are false, misleading, deceptive or likely to create an erroneous impression about its characteristics, health effects, 
hazards or emissions', including any figurative or other sign 'that directly or indirectly creates the false impression that a particular tobacco product is less harmful than other tobacco products'. ${ }^{72}$ FCTC defines 'tobacco advertising and promotion' to mean 'any form of commercial communication, recommendation or action with the aim, effect or likely effect of promoting a tobacco product or tobacco use either directly or indirectly'. (Article $1(\mathrm{c}))^{5}$ FCTC's Article 13 advertising, promotion and sponsorship provisions (Article 13(2)) $)^{5}$ urge parties to adopt comprehensive bans of all tobacco product advertising, promotion and sponsorship to reduce consumption of tobacco products. The Article 13 Guidelines for Implementation (Article 13) ${ }^{6}$ underscore that such a 'comprehensive ban' applies to all kinds of tobacco promotion without exception, including indirect advertising, acts that are likely to have a promotional effect and commercial communications. For example, in addition to traditional media and internet advertisements, Article 13 'advertising, promotion and sponsorship' restrictions include display of tobacco products at points of sale, packaging and product features (including colours, logos, pictures and materials), brand stretching and corporate social responsibility campaigns. (Article 13$)^{6}$

The Article 13 Guidelines are particularly relevant to current IQOS promotions, including its 'smoke-free future' campaign ${ }^{73}$ and its product features and marketing that appeal to youth and adolescents, including using packaging that uses colours, logos and materials that mimic iPhones, and selling IQOS in stores that imitate Apple computer stores. ${ }^{9}{ }^{10} 6162$ It is important to recognise that any advertising or promotion of IQOS, including in particular promotions of the holder alone or any other IQOS component that has been separated for marketing purposes from the essential tobacco sticks, is promoting tobacco within the meaning of the FCTC because it is not only likely to promote a tobacco product or use, but its specific aim is to promote use of the IQOS tobacco sticks (HeatSticks or HEETS). Neither the IQOS holder nor the IQOS tobacco sticks have any utility other than when used together. Following this reasoning, in April 2018, Lithuania's tobacco regulator fined a PMI subsidiary for advertising the IQOS device, determining the device is subject to the same advertising restrictions as other tobacco products ${ }^{74}$ based on its view that 'this device can only be used to smoke tobacco products'. ${ }^{75}$

As of May 2018, PMI was promoting IQOS as a less harmful alternative to cigarettes. ${ }^{39506076}$ Because these claims have not been substantiated with scientific evidence, they violate FCTC's Article 11 and Article 13 prohibitions. PMI's 'smokefree future' campaign ${ }^{73}$ appears designed to renormalise tobacco use, rather than to treat tobacco dependence or promote the end of tobacco. ${ }^{63}$ In February 2018, WHO issued a statement condemning BAT's promotional statements for its glo HTP implying that WHO endorsed glo as a less harmful alternative to conventional cigarettes and said, 'There is no evidence to demonstrate that HTPs are less harmful than conventional tobacco products. ${ }^{, 77}$

In countries that cannot enact comprehensive bans, Article 13(4) states that at a minimum, parties shall prohibit 'all forms of tobacco advertising, promotion and sponsorship that promote a tobacco product by any means that are false, misleading or deceptive or likely to create an erroneous impression about its characteristics, health effects, hazards, or emissions'. (Article 13(4)) ${ }^{5}$ Under this provision, countries should prohibit PMI from all forms of advertising or promoting IQOS. In the absence of such a prohibition, at a minimum, countries should not permit PMI to market IQOS with unsubstantiated explicit or implicit claims that it is safer than conventional cigarettes, including through using deceptive packaging or colours to alter consumers' perceptions of the product's harmfulness. ${ }^{78-83}$

Since scientific evidence does not support PMI's reduced risk claims about IQOS, they are false, misleading and/or deceptive and likely to create misperception about IQOS's health impacts, just as 'light' and 'mild' claims were found to mislead consumers. ${ }^{26}{ }^{27}$ Therefore, they are prohibited under Articles 11 and 13 .

\section{CONCLUSION}

Tobacco manufacturers are using unsubstantiated claims of reduced health risks associated with their new HTPs and aggressive marketing campaigns that are especially effective among youth and adolescents to introduce and market their latest versions of supposedly 'safer cigarettes'. The companies have not provided evidence to demonstrate that these new products are actually less harmful, and there is evidence that the companies' marketing claims mislead consumers. Companies have tried to evade existing laws intended to regulate tobacco products, including HTPs, by breaking apart the products and selling the components separately.

Because the tobacco sticks can only be used when attached to the HTP heating devices, sales prohibitions, youth access and advertising and labelling laws (including FCLAA restrictions that apply to cigarettes in the USA) should apply to the complete HTP system, including all components. Loopholes in laws and regulations (including the FDA's Deeming Rule) that would allow HTPs to evade tobacco control restrictions if the holder is sold separately from the tobacco stick should be eliminated. PMI's aggressive marketing techniques for IQOS using targeted

\section{What this paper adds}

Many tobacco companies are developing heated tobacco products (HTPs) that are being marketed with unsubstantiated claims of reduced harm compared with conventional cigarettes.

- Companies have sold the non-tobacco components of HTPs separately from the tobacco-containing components to exploit ambiguity in governments' 'tobacco product' definitions to evade tobacco control laws and public health restrictions.

- Philip Morris International has not submitted the adequate scientific evidence required by US law demonstrating that marketing IQOS in the USA would be 'appropriate for the protection of the public health', or demonstrating that IQOS is significantly less harmful to users than other tobacco products, that its labelling would not mislead consumers or that its marketing - with or without modified risk claimswould benefit the health of the population as a whole.

- The WHO Framework Convention on Tobacco Control (FCTC) provides a strong framework for parties outside the USA to enact and enforce laws to effectively regulate HTPs; parties should revise their laws to remove ambiguity and ensure that HTPs are covered by national laws.

- The USA and parties to the FCTC should ensure that all components of HTPs are regulated at least as stringently as tobacco products and are subject to all tobacco control laws that apply to other tobacco products, including restrictions on misleading labelling, advertising, promotion and sponsorship, sales to minors, price and taxation policies, and smokefree measures. 
customer interventions and sophisticated technologies to capture data, monitor use and convert customers should concern privacy and public health advocates. Policy-makers in places that do not prohibit the sale of HTPs should amend or enact comprehensive tobacco control laws that ensure HTPs are captured for the purposes of all tobacco product restrictions under the TCA and FCTC measures, including smokefree laws, advertising, promotion and sponsorship, packaging and labelling, taxation, and content regulation as appropriate. Under no circumstances should HTPs be treated less strictly than combustible tobacco products.

\section{Acknowledgements We thank Katherine Shats, LLM, LLB, BSC, Legal Advisor,} International Legal Consortium, Campaign for Tobacco-Free Kids, for assistance with the legal analysis of the FCTC and Stella A. Bialous, RN, DrPH, FAAN, Associate Professor, Social and Behavioral Sciences, School of Nursing, University of California, San Francisco, and Eric Lindblom, JD, Director for Tobacco Control and Food and Drug Law at the O'Neill Institute for National and Global Health Law for comments that greatly improved the manuscript.

Contributors Both authors conceptualised the study, contributed to the writing and revision, and approved the final version of the manuscript. LKL analysed the data.

Funding This work was supported by the US National Cancer Institute and Food and Drug Administration Center for Tobacco Products (P50 CA180890). The content is solely the responsibility of the authors and does not necessarily represent the official views of the National Institutes of Health or the FDA. The funding agencies played no role in design and conduct of the study; collection, management, analysis and interpretation of the data; preparation, review or approval of the manuscript; or decision to submit the manuscript for publication.

\section{Competing interests None declared.}

Patient consent Not required.

Provenance and peer review Not commissioned; externally peer reviewed.

Open access This is an open access article distributed in accordance with the Creative Commons Attribution Non Commercial (CC BY-NC 4.0) license, which permits others to distribute, remix, adapt, build upon this work non-commercially, and license their derivative works on different terms, provided the original work is properly cited, appropriate credit is given, any changes made indicated, and the use is non-commercial. See: http://creativecommons.org/licenses/by-nc/4.0/.

\section{REFERENCES}

1 Elias J, Dutra LM, St. Helen G, et al. Revolution or Redux? Assessing IQOS through a Precursor Product. Tob Control 2018;27(Suppl1):s102-s110.

2 Harlay J, 2016. What you need to know about Heat-not-Burn (HNB) cigarettes https:// www.vapingpost.com/2016/11/09/what-you-need-to-know-about-heat-not-burncigarettes-hnb/ (accessed 14 Feb 2018).

3 PMI. Science and innovation: our findings to Date. https://www.pmi.com/science-andinnovation/our-findings-to-date (accessed 18 Feb 2018).

4 U.S. Food and Drug Administration. Family Smoking Prevention and Tobacco Control Act, Pub. L. 111-31, 21 U.S.C. 387 et seq. 2009.

5 World Health Organization, 2005. WHO framework convention on tobacco control http://www.who.int/fctc/en/ (accessed 1 Feb 2018).

6 World Health Organization, 2013. WHO Framework Convention on Tobacco Control: Guidelines for Implementation http://www.who.int/fctc/guidelines/adopted/guidel_ 2011/en/ (accessed 1 Feb 2018).

7 FDA. Philip Morris Products S.A. Modified Risk Tobacco Product (MRTP) Applications. https://www.fda.gov/TobaccoProducts/Labeling/MarketingandAdvertising/ ucm546281.htm (accessed 13 May 2018).

8 PMI, 2017. Advisory Committee Briefing Materials: Tobacco Heating System (IQOS) Briefing Document https://www.fda.gov/downloads/AdvisoryCommittees/Committe esMeetingMaterials/TobaccoProductsScientificAdvisoryCommittee/UCM593108.pdf (accessed 14 Feb 2018).

9 Mathers A, Schwartz R, O'Connor S, et al. Marketing IQOS in a dark market. Tob Control 2018. doi: 10.1136/tobaccocontrol-2017-054216 (Epub ahead of print 03 May 2018).

10 Kim M. Philip Morris International introduces new heat-not-burn product, IQOS, in South Korea. Tob Control 2018:27:e76-8.

11 FDA, 2018. TPSAC Meeting Materials and Information, January 24-25, 2018: Transcript Day 1 https://www.fda.gov/downloads/AdvisoryCommittees/Committe esMeetingMaterials/TobaccoProductsScientificAdvisoryCommittee/UCM599234.pdf (accessed 16 May 2018).
12 Lasseter T, Wilson D, Wilson T, et al, 2018. Special Report: Philip Morris device knows a lot about your smoking habit https://www.reuters.com/article/us-tobacco-iqosdevice-specialreport/special-report-philip-morris-device-knows-a-lot-about-yoursmoking-habit-idUSKCN1IG1IY (accessed 16 May 2018).

13 FDA, 2018. TPSAC Meeting Materials and Information, January 24-25, 2018: Transcript Day 2 https://www.fda.gov/downloads/AdvisoryCommittees/Committe esMeetingMaterials/TobaccoProductsScientificAdvisoryCommittee/UCM599235.pdf (accessed 16 May 2018).

14 Connolly GN. A Reduced Risk Nicotine Delivery Device or a Device to Enhance and Control Abuse (Addiction) Potential through Manipulation of the Pattern of Nicotine Delivery? https://www.fda.gov/downloads/AdvisoryCommittees/CommitteesMeetin gMaterials/TobaccoProductsScientificAdvisoryCommittee/UCM594333.pdf (accessed 15 Feb 2018).

15 Henningfield J, Cone EJ, Buchhalter AR, et al. Evaluation of electronic nicotine delivery systems: Regulatory precedents from the FDA 2013 draft guidance for abusedeterrent opioids. Drug Alcohol Depend 2015;156:e94-5.

16 Lempert LK, Grana R, Glantz SA. The importance of product definitions in US e-cigarette laws and regulations. Tob Control 2016;25(e1):e44-51.

17 Code of Federal Regulations, Cigarettes, Smokeless Tobacco, And Covered Tobacco Products. Prohibition of Sale and Distribution to Persons Younger Than 18 Years of Age, Conditions of manufacture, sale, and distribution, 21 CFR 1140.16.

18 Code of Federal Regulations, Cigarettes, Smokeless Tobacco, and Covered Tobacco Products. Definitions, Sec. 1140.3, 21 CFR 1140.3.

19 Code of Federal Regulations. Tobacco Products Subject to FDA Authority, Scope, 21 CFR 1100.1.

20 Code of Federal Regulations, Cigarettes, Smokeless Tobacco, And Covered Tobacco Products. Prohibition of Sale and Distribution to Persons Younger Than 18 Years of Age, Additional responsibilities of retailers, 21 CFR 1140.14.

21 Federal Cigarette Labeling and Advertising Act. Definitions, 15 USC 1332.

22 Code of Federal Regulations, Cigarette Package and Advertising Warnings, Required warnings, 21 CFR 1141.10.

23 Federal Cigarette Labeling and Advertising Act. Definitions, Unlawful advertisements on medium of electronic communication, 15 USC 1335.

24 Family Smoking Prevention and Tobacco Control Act. Sec. 901, Pub. L. 111-31, 21 U.S.C. 387a. 2009.

25 Jenson D, Lester J, Berman ML. FDA's misplaced priorities: premarket review under the Family Smoking Prevention and Tobacco Control Act. Tob Control 2016;25:246-53.

26 United States v. Philip Morris USA Inc., 449 F. Supp.2d 1 (D.D.C. 2006). http://www. publichealthlawcenter.org/sites/default/files/resources/doj-final-opinion.pdf (accessed 1 Feb 2018)

27 Popova L, Lempert LK, Glantz SA. Light and mild redux: heated tobacco products' reduced exposure claims are likely to be misunderstood as reduced risk claims. Tob Control 2018;27(Suppl1):s87-s95.

28 PMI Science, 2017. Scientific update for smoke-free products https://www.pmiscience. com/system/files/publications/pmi_scientific_update_may_2017.pdf (accessed 2 Jan 2018).

29 Helen G, Jacob P, Nardone N, et al. IQOS: examination of Philip Morris International's claim of reduced exposure. Tob Control 2018;27(Supp|1):s30-s36.

30 Glantz SA. PMI's own in vivo clinical data on biomarkers of potential harm in Americans show that IQOS is not detectably different from conventional cigarettes. Tob Control 2018;27(Suppl1):s9-s12.

31 Glantz SA. PMI's Own Data on Biomarkers of Potential Harm in Americans Show that IQOS is Not Detectably Different from Conventional Cigarettes, so FDA Must Deny PMI's Modified Risk Claims, November 13, 2017. Public Comment, Docket Number: FDA-2017-D-3001, Tracking Number 1k1-8zrx-juh9. https://www.regulations.gov/ document?D=FDA-2017-D-3001-0108 (accessed 13 May 2018).

32 Moazed F, Chun L, Matthay MA, et al. Assessment of industry data on pulmonary and immunosuppressive effects of IQOS. Tob Control 2018;27(Suppl1):s20-s25.

33 Chun LF, Moazed F, Matthay MA, et al, 2017. IQOS emissions create risks of immunosuppression and pulmonary toxicity, so FDA should not issue an order permitting IQOS to be labeled or marketed with reduced risk claims, November 30, 2017. Public Comment, Docket Number: FDA-2017-D-3001, Tracking Number:1k1903a-mnpl https://www.regulations.gov/document?D=FDA-2017-D-3001-0134 (accessed 13 May 2018).

34 Chun L, Moazed F, Matthay M, et al. Possible hepatotoxicity of IQOS. Tob Control 2018;27(Supp|1):s39-s40.

35 Chun LF, Moazed F, Matthay MA, et al. PMI's MRTP application for IQOS does not adequately evaluate potential for hepatotoxicity risk, November 30, 2017. Public Comment, Docket Number: FDA-2017-D-3001, Tracking Number:1k1-9039-d91g. https://www.regulations.gov/document?D=FDA-2017-D-3001-0133 (accessed 13 May 2018).

36 Nabavizadeh P, Liu J, Havel CM, et al. Vascular endothelial function is impaired by aerosol from a single IQOS HeatStick to the same extent as by cigarette smoke. Tob Control 2018;27(Suppl1):s13-s19.

37 Springer ML, Nabavizadeh P, Mohammadi L. The evidence PMI presents in its MRTP application for IQOS is misleading and does not support the conclusion that IQOS will not harm endothelial function; independent research done in a more relevant physiological model shows that IQOS harms endothelial function as much as 
conventional cigarettes, November 20, 2017. Public Comment, Docket Number: FDA-2017-D-3001, Tracking Number 1k1-8zxa-mq9v. https://www.regulations.gov/ document?D=FDA-2017-D-3001-0118 (accessed 13 May 2018).

38 Davis B, Williams M, Talbot P. iQOS: evidence of pyrolysis and release of a toxicant from plastic. Tob Control 2018:doi: 10.1136/tobaccocontrol-2017-054104 (Epub ahead of print 13 Mar 2018).

39 O'Connell G, Wilkinson P, Burseg K, et al. Heated tobacco products create side-stream emissions: implications for regulation. J Environ Anal Chem 2015;2.

40 Helen G, Jacob P, Nardone N, et al. Because PMI application did not report the full range of HPHCs in IQOS aerosol, characterize HPHCs in sidestream emissions, include a non-targeted analysis of chemicals in emissions, or conduct clinical studies to describe exposure to toxicants during dual use with other tobacco products, FDA must deny PMI's application, November 29, 2017. Public Comment, Docket Number: FDA-2017-D-3001, Tracking Number 1k1-902j-m8kv. https://www.regulations.gov/ document?D=FDA-2017-D-3001-0129 (accessed 13 May 2018).

41 Auer R, Concha-Lozano N, Jacot-Sadowski I, et al. Heat-Not-Burn Tobacco Cigarettes: Smoke by Any Other Name. JAMA Intern Med 2017;177:1050-2.

42 Leigh NJ, Palumbo MN, Marino AM, et al. Tobacco-specific nitrosamines (TSNA) in heated tobacco product IQOS. Tob Control 2018;27(Suppl1):s37-s38.

43 Lasseter T, Bansal P, Wilson T, et al, 2017. Special Report: Scientists describe problems in Philip Morris e-cigarette experiments https:/www.reuters.com/article/us-tobaccoiqos-science-specialreport/special-report-scientists-describe-problems-in-philip-morrise-cigarette-experiments-idUSKBN1EE1GG (accessed 13 May 2018).

44 Lempert LK. Reuters published a special report on December 20, 2017 identifying several irregularities in Philip Morris' IQOS research. The kind of industry behavior documented in this report is questionable but not new, and FDA should consider this when making a determination on PMI's IQOS applications, December 21, 2017. Public Comment, Docket Number: FDA-2017-D-3001, Tracking Number 1k1-90gh-rnjp. https://www.regulations.gov/document?D=FDA-2017-D-3001-0168 (accessed 13 May 2018).

45 Max W, Sung H, Lightwood J, et al. Philip Morris's Population Health Impact Model is Based on Questionable Assumptions and Insufficient Health Impact Measures. Tobacco Control 2018 (Epub ahead of print 22 Nov 2018).

46 Max W, Lempert L, Sung H-Y, et al. Philip Morris's Population Health Impact Model Based on Questionable Assumptions and Insufficient Health Impact Measures Does Not Adequately Support its MRTP Application, November 22, 2017. Public Comment, Docket Number: FDA-2017-D-3001, Tracking Number 1k1-8zy0-6rfg. https://www. regulations.gov/document?D=FDA-2017-D-3001-0121 (accessed 13 May 2018).

47 McKelvey K, Popova L, Kim M, et al. Heated Tobacco Products Likely Appeal to Adolescents and Young Adults. Tobacco Control 2018;27(Suppl1):s41-s47.

48 Halpern-Felsher B, McKelvey K, Kim M, et al. PMI's MRTP Application for IQOS Does Not Consider IQOS's Appeal to Youth or Adolescents, or the Likelihood that Youth and Adolescents will Initiate Tobacco Use with IQOS or Use IQOS with Other Tobacco Products, December 7, 2017. Public Comment, Docket Number: FDA-2017-D-3001, Tracking Number 1k1-9087-458e. https://www.regulations.gov/document?D=FDA2017-D-3001-0148 (accessed 13 May 2018).

49 National Academies of Sciences, Engineering, and Medicine. Public health consequences of E-Cigarettes. Washington, DC: The National Academies Press, 2018.

50 McKelvey K, Popova L, Kim M, et al. IQOS labelling will mislead consumers. Tob Control 2018;27(Suppl1):s48-s54.

51 Lempert LK, Popova L, Halpern-Felsher B, et al. Because PMI has not demonstrated that IQOS is associated with lower risks, FDA should not permit modified exposure claims, because such claims are likely to be misunderstood as modified risk claims, December 11, 2017. Public Comment, Docket Number: FDA-2017-D-3001, Tracking Number 1k1-90at-5wj2. https://www.regulations.gov/document?D=FDA-2017-D3001-0154 (accessed 13 May 2018).

52 El-Toukhy S, Baig SA, Jeong M, et al. Impact of modified risk tobacco product claims on beliefs of US adults and adolescents. Tob Control 2018;27(Suppl1):s62-s69.

53 PMI. PMI 2017 Annual Report. http://media.corporate-ir.net/media_files/IROL/14/ 146476/2018/AR/PMIAR2017-Final/index.html (accessed 13 May 2018).

54 PMI. Our Tobacco Heating System - IQOS. https://www.pmi.com/smoke-free-products/ iqos-our-tobacco-heating-system (accessed 1Feb 2018).

55 World Health Organization. WHO Framework Convention on Tobacco Control Secretariat's statement on the launch of the Foundation for a Smoke-Free World, 19 September 2017. http://www.who.int/fctc/mediacentre/press-release/secretariatstatement-launch-foundation-for-a-smoke-free-world/en/ (accessed 12 Feb 2018).

56 Conference of the Parties to the WHO FCTC. Further development of the partial guidelines for implementation of Articles 9 and 10 of the WHO FCTC, FCTC/COP/7/9, 12 July 2016. http://www.who.int/fctc/cop/cop7/FCTC_COP_7_9_EN.pdf?ua=1\& ua $=1$ (accessed 14 Feb 2018)
57 World Health Organization. Heated tobacco products (HTPs) information sheet. http:// www.who.int/tobacco/publications/prod_regulation/heated-tobacco-products/en/ (accessed 14 Feb 2018)

58 Siegel-Itzkovich J, 2017. Justice Ministry says IQOS product will be treated as ordinary tobacco, The Jerusalem Post https://www.jpost.com/Business-and-Innovation/Healthand-Science/Justice-Ministry-says-iQOS-product-will-be-treated-as-ordinary-tobacco485912 (accessed 21 May 2018)

59 Roberts C, 2018. IQOS cigarettes to be taxed as regular cigarettes, Israel National News http://www.israelnationalnews.com/News/News.aspx/243034 (accessed 21 May 2018).

60 Hefler M. The changing nicotine products landscape: time to outlaw sales of combustible tobacco products? Tob Control 2018;27:1-2.

61 Hair EC, Bennett M, Sheen E, et al. Examining perceptions about IQOS heated tobacco product: consumer studies in Japan and Switzerland. Tob Control 2018;27(Suppl1):s7 $0-s 73$.

62 Nyman AL, Weaver SR, Popova L, et al. Awareness and use of heated tobacco products among US adults, 2016-2017. Tob Control 2018;27(Suppl1):s55-s61.

63 European Network for Smoking and Tobacco Prevention. Position Paper: Heat Not Burn Tobacco \& Related Products. 2017;24 http://ensp.network/position-paper-heatnot-burn-tobacco-related-products/.

64 Chaffee BW, Watkins SL, Glantz SA. Electronic Cigarette Use and Progression From Experimentation to Established Smoking. Pediatrics 2018;141:e20173594.

65 Dutra LM, Glantz SA. Electronic cigarettes and conventional cigarette use among U.S. adolescents: a cross-sectional study. JAMA Pediatr 2014;168:610-7.

66 Watkins SL, Glantz SA, Chaffee BW. Association of Noncigarette Tobacco Product Use With Future Cigarette Smoking Among Youth in the Population Assessment of Tobacco and Health (PATH) Study, 2013-2015. JAMA Pediatr 2018;172:181-7.

67 Amul GGH, Pangestu Pang T. Progress in Tobacco Control in Singapore: Lessons and Challenges in the Implementation of the Framework Convention on Tobacco Control. Asia Pac Policy Stud 2018;5:102-21.

68 Therapeutic Goods Administration, Dept. of Health and Ageing, Australian Government. Poisons Standard. https://www.tga.gov.au/publication/poisons standard-susmp (accessed 17 Feb 2018).

69 Conference of the Parties to the WHO FCTC. Decision: Control and prevention of waterpipe tobacco products, FCTC/COP7(4). http://www.who.int/fctc/cop/cop7/FCTC COP7(4)_EN.pdf?ua=1 (accessed 20 Feb 2018).

70 Jawad M, El Kadi L, Mugharbil S, et al. Waterpipe tobacco smoking legislation and policy enactment: a global analysis. Tob Control 2015;24(Suppl 1):i60-i65.

71 Translations of the laws can be found at. https://www.tobaccocontrollaws.org/files/ live/ (accessed 12 Feb 2018)

72 World Health Organization, 2005. WHO Framework Convention on Tobacco Control, Article 11 http://www.who.int/fctc/en/ (accessed 1 Feb 2018).

73 PMI. Our goal is to design a smoke-free future. https://www.pmi.com/who-we-are/ our-goal-and-strategies (accessed 1 Feb 2018)

74 ECiglntelligence. Philip Morris set to appeal against Lithuanian ban on advertising IQOS, Regulatory briefing, 23 April 2018. https://ecigintelligence.com/philip-morrisset-to-appeal-against-lithuanian-ban-on-advertising-iqos/ (accessed 5 Jun 2018).

75 Sytas A R, 2018. Philip Morris may have breached Lithuania's advertising rules with new smoking device https://www.reuters.com/article/us-tobacco-iqos-marketing/ philip-morris-may-have-breached-lithuanias-advertising-rules-with-new-smokingdevice-idUSKCN1G51SB (accessed 22 Feb 2018).

76 BBC Radio. Philip Morris could move from normal cigarettes. http://www.bbc.co.uk/ programmes/p04jhnsw (accessed 19 Feb 2018).

77 World Health Organization. WHO condemns misleading use of its name in marketing of heated tobacco products. http://www.who.int/tobacco/communications/ statements/name-marketing-tobacco/en/ (accessed Feb 14, 2018).

78 Wakefield M, Morley C, Horan JK, et al. The cigarette pack as image: new evidence from tobacco industry documents. Tob Control 2002;11(Suppl 1):i73-80.

79 Hammond D, Dockrell M, Arnott D, et al. Cigarette pack design and perceptions of risk among UK adults and youth. Eur J Public Health 2009;19:631-7.

80 Bansal-Travers M, Hammond D, Smith P, et al. The impact of cigarette pack design, descriptors, and warning labels on risk perception in the U.S. Am J Prev Med 2011:40:674-82.

81 Mutti S, Hammond D, Borland R, et al. Beyond light and mild: cigarette brand descriptors and perceptions of risk in the International Tobacco Control (ITC) Four Country Survey. Addiction 2011;106:1166-75.

82 Connolly GN, Alpert HR. Has the tobacco industry evaded the FDA's ban on 'Light' cigarette descriptors? Tob Control 2014:23:140-5.

83 Lempert LK, Glantz S. Packaging colour research by tobacco companies: the pack as a product characteristic. Tob Control 2017:26:307-15. 